Article

\title{
Long-Term Dietary Taurine Lowers Plasma Levels of Cholesterol and Bile Acids
}

\author{
Ryoma Tagawa ${ }^{1,+}$, Masaki Kobayashi ${ }^{1, *,+}{ }^{\mathbb{D}}$, Misako Sakurai ${ }^{1}$, Maho Yoshida ${ }^{1}$, Hiroki Kaneko ${ }^{1}$, \\ Yuhei Mizunoe $^{2}{ }^{\mathbb{D}}$, Yuka Nozaki ${ }^{1}$, Naoyuki Okita ${ }^{3}$, Yuka Sudo ${ }^{1}$ and Yoshikazu Higami ${ }^{1,4, *}$
}

1 Department of Medicinal and Life Sciences, Faculty of Pharmaceutical Sciences, Tokyo University of Science, Chiba 278-8510, Japan; 3b13648@alumni.tus.ac.jp (R.T.); 3b18536@alumni.tus.ac.jp (M.S.); 3b17667@alumni.tus.ac.jp (M.Y.); 3a11019@alumni.tus.ac.jp (H.K.); nozaki@rs.tus.ac.jp (Y.N.); yukafeatkoro@me.com (Y.S.)

2 Department of Internal Medicine Endocrinology and Metabolism, Faculty of Medicine, University of Tsukuba, Tsukuba 305-8575, Japan; ymizunoe@md.tsukuba.ac.jp

3 Division of Pathological Biochemistry, Faculty of Pharmaceutical Sciences, Sanyo-Onoda City University, Yamaguchi 756-0884, Japan; nokita7@rs.tusy.ac.jp

4 Division of Integrated Research, Research Institute for Biomedical Sciences, Tokyo University of Science, Chiba 278-0022, Japan

* Correspondence: kobayashim@rs.tus.ac.jp (M.K.); higami@rs.tus.ac.jp (Y.H.); Tel.: +81-4-7121-3676 (M.K.); +81-4-7121-3675 (Y.H.)

+ These authors contributed equally to this work.

check for updates

Citation: Tagawa, R.; Kobayashi, M.; Sakurai, M.; Yoshida, M.; Kaneko, H.; Mizunoe, Y.; Nozaki, Y.; Okita, N.; Sudo, Y.; Higami, Y. Long-Term Dietary Taurine Lowers Plasma Levels of Cholesterol and Bile Acids. Int. J. Mol. Sci. 2022, 23, 1793. https://doi.org/10.3390/ijms 23031793

Academic Editor: Giovanni Tarantino

Received: 25 December 2021

Accepted: 2 February 2022

Published: 4 February 2022

Publisher's Note: MDPI stays neutral with regard to jurisdictional claims in published maps and institutional affiliations.

Copyright: (C) 2022 by the authors. Licensee MDPI, Basel, Switzerland. This article is an open access article distributed under the terms and conditions of the Creative Commons Attribution (CC BY) license (https:// creativecommons.org/licenses/by/ $4.0 /)$.

\begin{abstract}
Cholesterol is an essential lipid in vertebrates, but excess blood cholesterol promotes atherosclerosis. In the liver, cholesterol is metabolized to bile acids by cytochrome P450, family 7, subfamily a, polypeptide 1 (CYP7A1), the transcription of which is negatively regulated by the ERK pathway. Fibroblast growth factor 21 (FGF21), a hepatokine, induces ERK phosphorylation and suppresses Cyp7a1 transcription. Taurine, a sulfur-containing amino acid, reportedly promotes cholesterol metabolism and lowers blood and hepatic cholesterol levels. However, the influence of long-term feeding of taurine on cholesterol levels and metabolism remains unclear. Here, to evaluate the more chronic effects of taurine on cholesterol levels, we analyzed mice fed a taurinerich diet for 14-16 weeks. Long-term feeding of taurine lowered plasma cholesterol and bile acids without significantly changing other metabolic parameters, but hardly affected these levels in the liver. Moreover, taurine upregulated Cyp7a1 levels, while downregulated phosphorylated ERK and Fgf21 levels in the liver. Likewise, taurine-treated Hepa1-6 cells, a mouse hepatocyte line, exhibited downregulated $F g f 21$ levels and upregulated promoter activity of Cyp7a1. These results indicate that taurine promotes cholesterol metabolism by suppressing the FGF21/ERK pathway followed by upregulating Cyp7a1 expression. Collectively, this study shows that long-term feeding of taurine lowers both plasma cholesterol and bile acids, reinforcing that taurine effectively prevents hypercholesterolemia.
\end{abstract}

Keywords: taurine; cholesterol; bile acid; FGF21; ERK; CYP7A1

\section{Introduction}

Cholesterol is an essential lipid for lipid bilayers and biosynthesis of steroid hormones. However, obese patients often show a high blood cholesterol level, which promotes atherosclerosis [1,2]. The blood levels of cholesterol are strictly regulated mainly by the liver, which releases cholesterol in the form of very low-density lipoprotein (VLDL) and takes in cholesterol through the low-density-lipoprotein (LDL) receptor [3]. Cholesterol is converted to bile acids, including cholic acids and deoxycholic acids, in the liver; steroid hormones, including sex hormones, in the testes or ovaries; and glucocorticoid, in the adrenal cortex. Interestingly, these metabolites modulate the synthesis of each other. Specifically, estradiol and progesterone reportedly regulate the synthesis of bile acids in hepatocytes, while 
bile acids are involved in various steps of the synthetic pathway of glucocorticoids [4-6]. Bile acids are secreted to the duodenum, where they support the activity of lipase by forming micelles with lipids during digestion [7]. In fact, the deletion of sterol 12-alphahydroxylase, an enzyme involved in the synthesis of bile acids, causes lowered levels of bile acid and impaired absorption of lipids in mice [8,9]. Most bile acids are reabsorbed in the small intestinal tract and retransported to the liver [10]. Bile acids are also known as signaling metabolites, which regulate lipid and glucose metabolism [11-14]. In addition, bile acids contribute to energy expenditure associated with thermogenesis in brown adipose tissue [15]. On the basis of the above, altered bile acid synthesis can affect systemic metabolism, as well as lipid digestion.

The metabolic pathway of cholesterol is classified into the classical pathway responsible for bile acid synthesis in the liver, and the alternative pathway mainly responsible for the synthesis of bile acids and steroid hormones in macrophages or the adrenal cortex [16]. Liver expresses all of the enzymes involved in the classical pathway [16]. Among these enzymes, cytochrome P450, family 7, subfamily a, polypeptide 1 (CYP7A1) is the rate-limiting enzyme of the conversion of cholesterol into bile acids [17-22]. Humans with CYP7A1 lossof-function mutations exhibit high levels of circulating LDL cholesterol [23]. The expression of Cyp7a1 is reportedly regulated by bile acids as follows. Bile acids activate farnesoid X receptor (FXR), a nuclear receptor, and induce its downstream pathways, including small heterodimer partner (SHP) and liver receptor homolog-1 (LRH-1), thereby suppressing the expression of Cyp7a1 in the liver. To explain this signal in brief, the binding of bile acids to FXR in the liver transcriptionally induces SHP, which inhibits the transcriptional activity of LHR-1, leading to suppressed expression of Cyp7a1 [24]. In addition to this, bile acids also activate FXR and promote the secretion of fibroblast growth factor 15/19 (FGF15/19) in the ileum. Circulating FGF15/19 binds to the FGF receptor 4 (FGFR4)-Klotho beta (KLB) complex, which is abundant in the liver, and suppresses expression of the Cyp7a1 gene. It has also been reported that the members of MAPK cascades, such as extracellular signalregulated kinase (ERK) and c-Jun N-terminal kinase (JNK), downregulate the expression of Cyp7a1 [25].

Fibroblast growth factor 21 (FGF21) is a hepatokine that regulates lipid and glucose metabolism [26,27]. After secretion from the liver, FGF21 mainly binds to the FGF receptor 1 (FGFR1) and beta-klotho (KLB) receptor complex in target tissues, such as white adipose tissue (WAT) and muscle, which in turn activates the downstream signals [20,28,29]. FGF21 also protects against hepatic insulin resistance and steatosis in obese mice and regulates glycogen synthesis and ketone body production in the liver [30-33]. Chen et al. demonstrated that, in primary hepatocytes and several rodent models, FGF21 suppresses expression of the Cyp7a1 gene via the induction of ERK phosphorylation [34]. FGF21 is also a well-known stress-responsive cytokine [35]. In fact, previous studies showed that FGF21 levels are elevated in the blood of obese individuals and liver in patients with nonalcoholic fatty liver disease $[36,37]$.

Taurine $\left(\mathrm{NH}_{3}{ }^{+}-\mathrm{CH}_{2}-\mathrm{CH}_{2}-\mathrm{SO}_{3}{ }^{-}\right)$, a sulfur-containing amino acid that is not used for protein synthesis and exists as a free amino acid, is endogenously made from cysteine or methionine, or exogenously provided by the diet $[38,39]$. Taurine is known to regulate oxidative stress, osmotic pressure, intracellular calcium concentration, and autophagy [40-43]. Previous studies have shown that taurine regulates metabolic pathways of glucose and lipids. For example, taurine improves hyperglycemia in diabetic model animals by modifying glucagon activity, insulin sensitivity, and insulin secretion [44]. Taurine also inhibits fatty acid biosynthesis and enhances the catabolism of triglycerides in the liver, thereby preventing high-fat-diet-induced hepatic steatosis [45]. In addition to the above, many findings support the effects of taurine on the levels of cholesterol and its metabolism [46]. Actually, a taurine-supplemented diet reportedly promotes cholesterol degradation, thereby lowering serum and hepatic cholesterol levels [10,47]. Moreover, taurine-supplemented water is reported to increase hepatic LDL receptors and allow its internalization and degradation [48]. Although accumulated evidence has shown that taurine can lower plasma 
cholesterol levels, many of these studies evaluated its effects using animals fed taurine for a relatively short period (e.g., 2 weeks) [49]. Hence, current findings fail to sufficiently demonstrate the continuous involvement of taurine in cholesterol metabolism. In the present study, to evaluate the more chronic effects of taurine on cholesterol metabolism, we analyzed cholesterol-related metabolic parameters and pathways in mice fed taurine for a long period.

\section{Results}

\subsection{Taurine Lowered Plasma Levels of Cholesterol and Bile Acids}

Taurine did not affect body weight, food intake, or the weight of metabolic tissues, such as the liver, epididymal WAT (eWAT), and inguinal subcutaneous WAT (iWAT) (Figure S1A-F, see Supplementary Materials). To evaluate the basal metabolic rate and glucose metabolism in the whole body, we calculated the respiratory exchange ratio (RER) from respiration measurements and performed a glucose tolerance test (GTT) and an insulin tolerance test (ITT) in control diet (Chow) and taurine-supplemented diet (TauD) groups. The results showed that these parameters were not significantly changed (Figure S2A-E). Likewise, basal plasma glucose levels also showed no significant difference between the two groups (Figure S2F). These results indicate that taurine exerted little influence on whole-body metabolism in this model. Subsequently, we measured plasma lipid parameters, cholesterol, bile acids, triglycerides (TG), and non-esterified fatty acids (NEFA). The TauD group showed lower plasma levels of cholesterol and total bile acids, but no significant change in TG and NEFA levels (Figure 1A-D). In contrast, the levels of cholesterol and bile acids in the liver and bile acids in feces were unchanged between the Chow and TauD groups (Figure 1E-G). These findings suggest that taurine strongly induced the catabolism of cholesterol and bile acid transported into the liver, resulting in their lowered plasma levels.
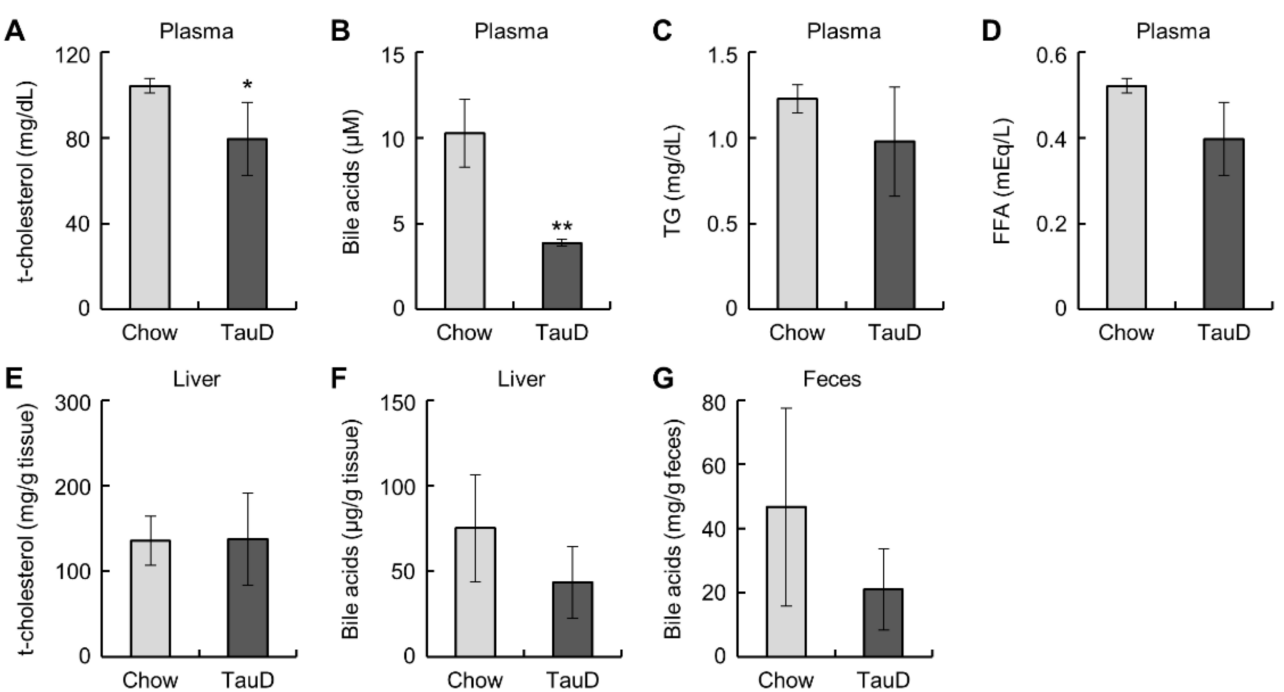

Figure 1. Taurine lowered plasma cholesterol and bile acids: Plasma total cholesterol (t-cholesterol) $(\mathrm{n}=5)(\mathbf{A})$, bile acids $(\mathrm{n}=4)(\mathbf{B})$, triglyceride $(\mathrm{TG})(\mathrm{n}=5)(\mathbf{C})$, non-esterified fatty acids (NEFA) $(\mathrm{n}=5)$ $(D)$, t-cholesterol $(n=10-11)(E)$, and bile acids $(n=5)(F)$ in the liver, and bile acids $(\mathbf{G})$ in feces $(\mathrm{n}=4)$ of Chow and TauD groups. Values represent means \pm SD. Differences between values were statistically evaluated by Student's $t$-test. ${ }^{*} p<0.05,{ }^{* *} p<0.01$ vs. Chow.

2.2. Taurine Induced the Expression of the Cyp7a1 Gene and Suppressed the FGF21-ERK Signal in the Liver

To evaluate the impact of taurine on cholesterol metabolism, we initially analyzed the expression of the Cyp7a1 gene, which encodes a rate-limiting enzyme converting cholesterol into bile acid, in the liver. In the TauD group, Cyp7a1 levels were markedly 
upregulated (Figure 2A). Next, we examined the levels of phosphorylated ERK and JNK, negative regulators of $C y p 7 a 1$, in the liver. Although the phosphorylation levels of JNK were unchanged, those of ERK were decreased in the TauD group (Figure 2B). Subsequently, we analyzed the hepatic levels of $F g f 21$, an upstream regulator of ERK. The results showed that taurine downregulated the hepatic levels of Fgf21 (Figure 2C). In agreement with this, plasma FGF21 levels were also decreased in the TauD group (Figure 2D). These findings suggest that taurine upregulated expression of the Cyp7a1 gene by suppressing the FGF21/ERK pathway in the liver.
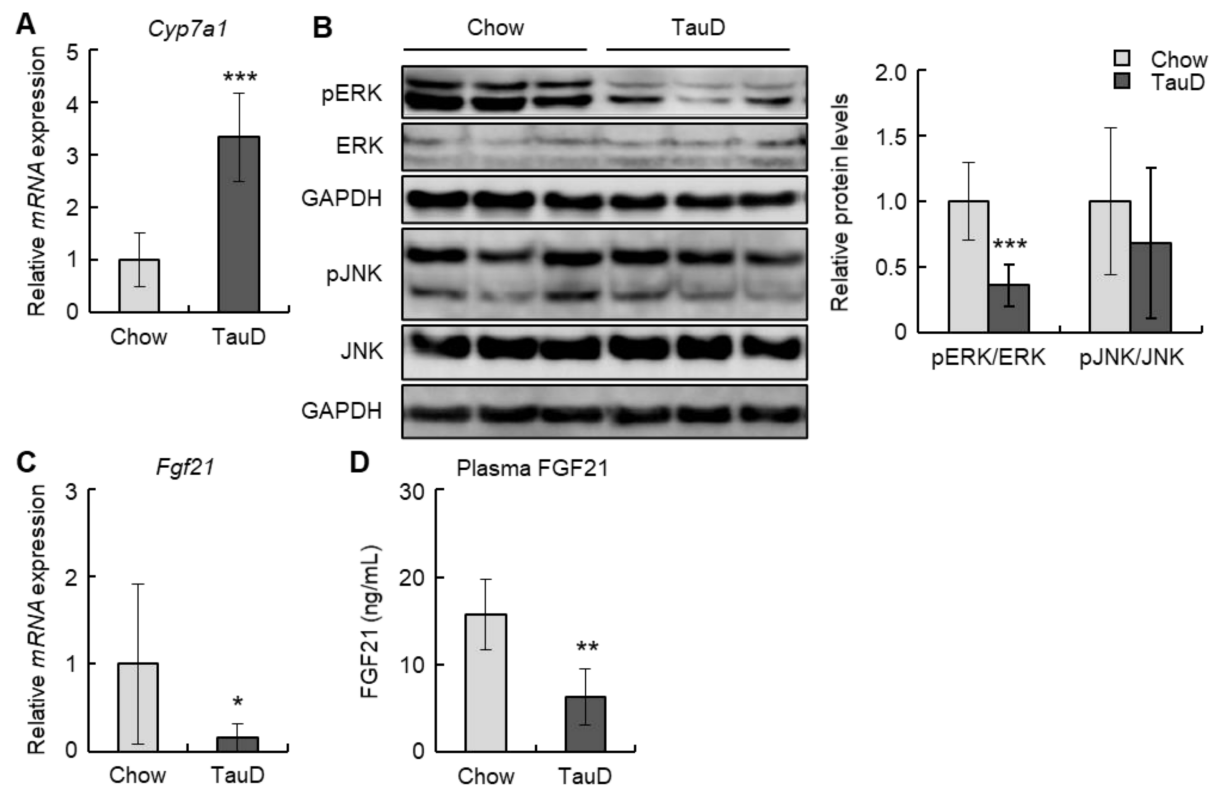

Figure 2. Taurine downregulated FGF21/ERK pathway and upregulated Cyp7a1 transcription in the liver: (A) The expression of Cyp7a1 mRNA in the liver was analyzed by real-time RT-PCR $(n=6)$. (B) Total protein extracted from the liver was analyzed by immunoblotting using the shown antibodies $(n=6)$. The left panels show representative images. The right graphs show quantitative data. GAPDH was used as a loading control. (C) The expression of Fgf21 mRNA in the liver was analyzed by real-time RT-PCR $(n=6)$. (D) Plasma FGF21 was quantified using ELISA $(n=6)$. Data of real-time RT-PCR were normalized to Tbp levels. Values represent means $\pm \mathrm{SD}$. Differences between values were statistically evaluated by Student's $t$-test. ${ }^{*} p<0.05,{ }^{* *} p<0.01,{ }^{* * *} p<0.001$ vs. Chow.

\subsection{Taurine Suppressed the Expression of FGF21 and Enhanced the Activity of Cyp7a1 Promoter in Hepa1-6 Cells}

To confirm the effects of taurine on the FGF21/ERK pathway in the liver, we examined Hepa1-6 cells treated with taurine. The phosphorylation levels of ERK were decreased, but not significantly, in $3 \mathrm{mM}$ taurine-treated Hepa1-6 cells (Figure 3A). Similar to the results obtained from in vivo experiments, taurine downregulated the expression of the Fgf21 gene (Figure 3B). Next, we performed a luciferase assay to examine the promoter activity of Cyp7a1 in Hepa1-6 cells treated with taurine because the detected expression levels of Cyp7a1 were insufficient for quantitative evaluation. The results showed that taurine enhanced Cyp7a1 promoter activity (Figure 3C). These findings suggest that taurine suppressed the expression of FGF21 and induced Cyp7a1 transcription. 
A
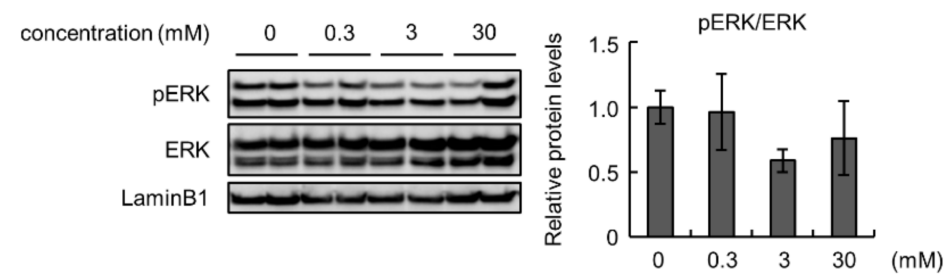

B
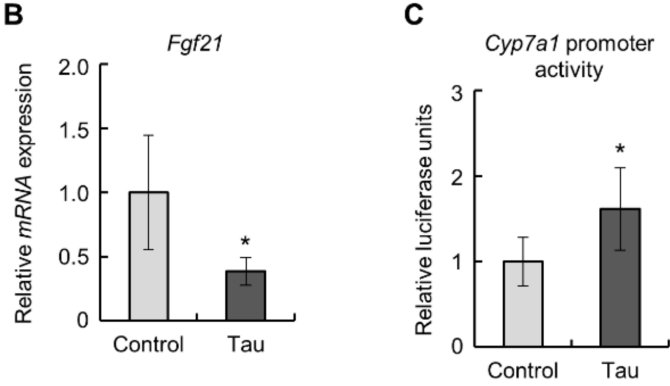

Figure 3. Taurine downregulated $F d f 21$ levels and induced Cyp7a1 promoter activity in Hepa1-6 cells: (A) Total protein extracted from Hepa1-6 cells treated with the indicated concentrations of taurine for $24 \mathrm{~h}$ was analyzed by immunoblotting using the shown antibodies $(n=4)$. The left panels show representative images. The right graphs show quantitative data. LaminB1 was used as a loading control. (B) The expression of Fgf 21 mRNA in $10 \mathrm{mM}$ taurine-treated Hepa1-6 cells (Tau) was analyzed by real-time RT-PCR. Data were normalized to Rps18 $(\mathrm{n}=6)$. (C) Luciferase assay of Cyp7a1 in $10 \mathrm{mM}$ taurine-treated Hepa1-6 cells (Tau). Relative luminescent units (RLU) were calculated as shown in the Materials and Methods section $(n=4)$. Values represent means \pm SD. Differences between values were statistically evaluated by Dunnett's test $(\mathbf{A})$ or Student's $t$-test $(\mathbf{B}, \mathbf{C}) .{ }^{*} p<0.05$ vs. Control.

\section{Discussion}

In the present study, we demonstrated that long-term feeding of taurine lowered plasma cholesterol and suppressed the FGF21/ERK pathway in mice. The former effect is consistent with previous articles reporting that taurine prevents hypercholesterolemia [47,48]. Murakami et al. showed that taurine enhances the uptake of LDL cholesterol into the liver, resulting in lowered plasma cholesterol [48]. Given our results showing that taurine did not alter cholesterol levels in the liver (Figure 1E,F), taurine is likely to induce the catabolism of cholesterol transported into the liver, as well as its uptake. Moreover, taurine did not change the contents of bile acids, a catabolic product of cholesterol, in the liver and feces (Figure 1F,G), implying that taurine may promote the transport of produced bile acids into the blood circulation. However, plasma levels of bile acids were rather reduced in the taurine-fed group (Figure 1B). In general, taurine conjugates with bile acids, thereby promoting bile excretion by increasing their water solubility into bile [50,51]. In fact, Miyazaki et al. reported that a taurine-deficient diet decreased bile acid excretion into bile in cats, which have a low ability to biosynthesize taurine [52]. Therefore, it is conceivable that taurine can enhance not only the catabolism of cholesterol but also the enterohepatic circulation of bile acids via conjugation, leading to lowered plasma levels of cholesterol and bile acids.

Taurine lowered the levels of plasma FGF21 and Fgf21 mRNA in the liver and Hepa16 cells (Figures 2C,D and 3B). This result is partially supported by a previous report describing that taurine suppressed the level of FGF21 in the liver of cafeteria-diet-fed rats [53]. Taurine also significantly enhanced Cyp7a1 transcription and suppressed the phosphorylation of ERK in the liver (Figure 2A,B). FGF21 has been proven to suppress Cyp7a1 mRNA expression in hepatocytes [20,34]. In contrast, Keinicke et al. reported that FGF21 administration upregulated Cyp7a1 mRNA expression in the liver of mice with diet-induced obesity [54]. Zhang et al. also demonstrated that adeno-associated 
virus-mediated overexpression of $F g f 21$ in mice increased liver expression of Cyp7a1 [55]. However, it has also been reported that FGF21 administration exerts no influence on this expression [56,57]. These controversial findings suggest that differences in experimental conditions can markedly affect the relationship between FGF21 and Cyp7a1 expression. Moreover, although the FGF21-ERK signal generally requires the binding of FGF21 to FGFR1, FGFR1 is hardly expressed in the liver [13]. Hence, the above effects of FGF21 in hepatocytes can be mediated by other FGFRs, for example, FGFR3, which is reportedly expressed in the liver and bound by FGF21 $[58,59]$.

Cyp7a1 is positively regulated by hepatocyte nuclear factor $4 \alpha$ (HNF $4 \alpha$ ), whose activity is known to be suppressed by ERK via the induction of its phosphorylation and extranuclear transport [60,61]. In Hepa1-6 cells, taurine activated Cyp7a1 transcription (Figure 3C). The Cyp7a1 promoter region used in this study contains an HNF4 $\alpha$-binding site [25]. Furthermore, taurine reportedly increases the level of HNF4 $\alpha$ protein and its transcriptional activity for Cyp7a1 [62]. However, in our analysis, taurine failed to significantly change the nuclear amount of HNF4 $\alpha$ in Hepa1-6 cells despite downregulated Cyp7a1 (Figure S5). The transcriptional activity of HNF4 $\alpha$ requires not only its nuclear localization but also homodimer formation [63]. ERK has been demonstrated to inhibit homodimer formation by the phosphorylation of HNF4 $\alpha$ [60]. Based on these findings, the unchanged nuclear HNF $4 \alpha$ in taurine-treated Hepa1-6 cells implies that taurine may maintain homodimer formation of HNF4 $\alpha$ via suppressed ERK activity, resulting in upregulated transcription of Cyp7a1.

In addition to the above pathways, the transcription of Cyp7a1 is regulated by a negative feedback loop containing the following members of the nuclear receptor family: FXR, SHP, and LRH-1 [24]. Our results showed that taurine exerted no effect on the mRNA levels of Fxr, Shp, and Lrh-1 in the liver, indicating that taurine-induced increase in Cyp7a1 expression is not highly relevant to this signal pathway (Figure S3). Transcriptional regulation of Cyp7a1 also includes the FGF15/19-FGFR4-KLB signal. Feeding-induced bile acids increase Fof15/19 expression in the ileum, thereby elevating serum FGF15/19 levels [64]. The binding of FGF15/19 to FGFR4 suppresses the expression of Cyp7a1 in the liver [24]. In our analysis, taurine did not alter the levels of $F g f 15 / 19$ in the ileum (Figure S4), supported by the result of the amount of bile acids in feces remaining unchanged (Figure 1G). This is inconsistent with a recent study showing that taurine decreased Fgf15 in the ileum [65]. This discrepancy may be due to differences in the duration of feeding of taurine. Taking these findings together, it is conceivable that long-term feeding of taurine induces an increase in Cyp7a1 expression and a reduction in plasma cholesterol levels, which may be mainly attributed to the FGF21-ERK signal.

Apart from CYP7A1, cholesterol is known to be metabolized by $11 \beta$-hydroxysteroid dehydrogenase 1 (11B-HSD1), an enzyme that interconverts cortisone and cortisol, thereby regenerating active glucocorticoids [66]. To be exact, 7-oxocholesterol is a substrate of 11B-HSD1 $[67,68]$. Taurine reportedly prevents glucocorticoid-induced osteonecrosis and muscle atrophy, which implies that taurine may affect the activity of 11B-HSD1 and suppress glucocorticoid-induced physiological reactions [69,70]. Despite no direct evidence of the relationship between taurine and 11B-HSD, taurine may contribute to cholesterol metabolism via not only increased expression of Cyp7a1, but also regulation of the activity of 11B-HSD1.

In conclusion, our data showed that long-term dietary taurine lowered plasma cholesterol and bile acids, probably by promoting cholesterol metabolism via the induction of CYP7A1. Additionally, taurine suppressed the production of FGF21 in the liver (Figure 4). Although FGF21 is known to contribute to systemic glucose metabolism as mentioned above, there was no difference in glucose tolerance between the Chow and TauD groups. Thus, a taurine-induced decrease in FGF21 could locally affect cholesterol metabolism in the liver in an autocrine or paracrine manner. Given that bile acids are metabolites of cholesterol, a taurine-induced decrease in bile acids with induced-cholesterol metabolism can reflect more efficient prevention of hypercholesterolemia. Taurine is easily taken in 
from seafood diets and available supplements in daily life. Furthermore, few side effects of taurine have been reported, which is consistent with our results that TauD groups exhibited no observable side effects. These features confer advantages for the use of taurine in continuously lowering blood cholesterol.

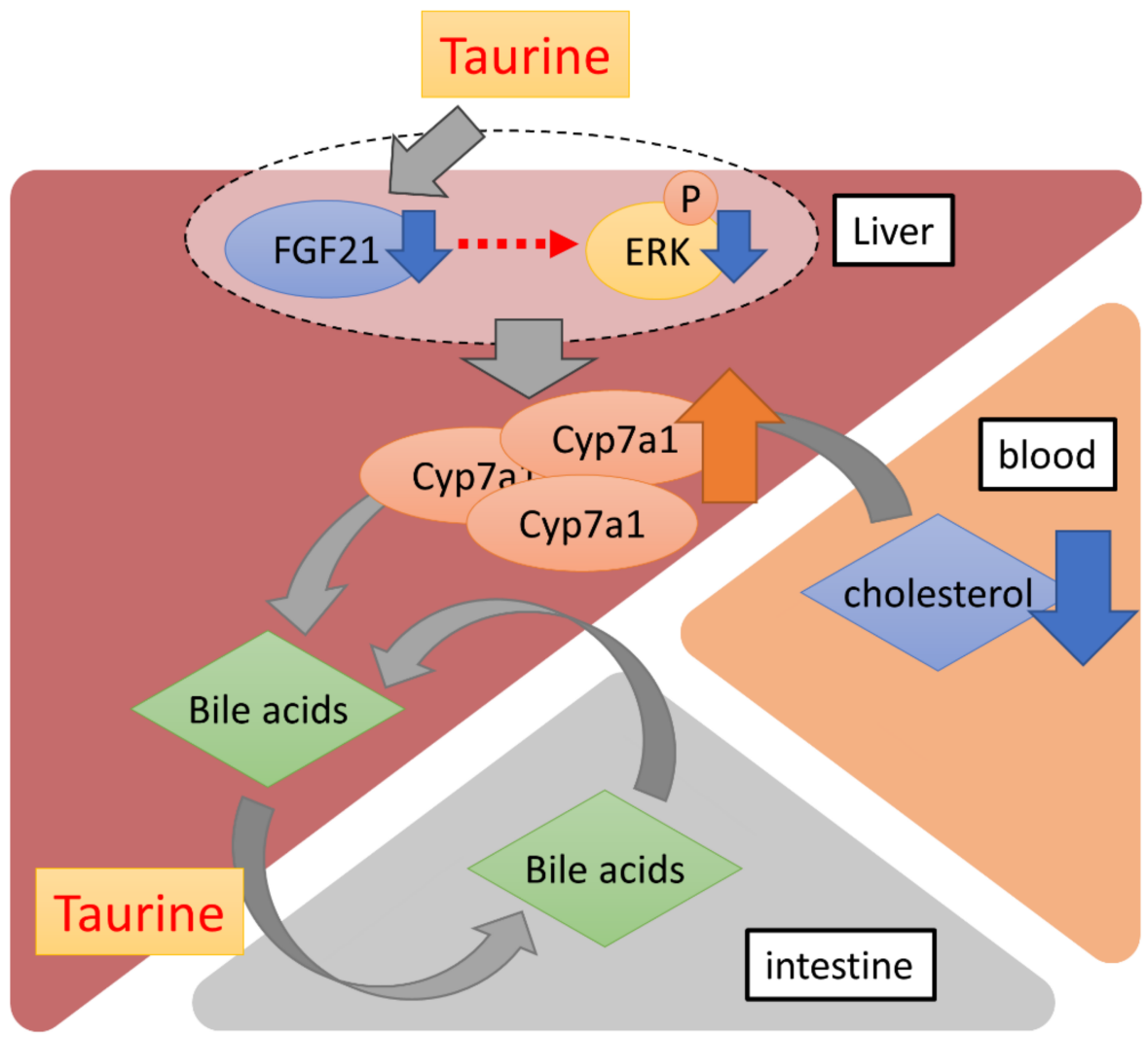

Figure 4. A schematic diagram of the effects of long-term dietary taurine. Taurine upregulates the transcriptional activity of Cyp7a1 by suppressing FGF21 production in the liver. Bile acids are converted from blood cholesterol by CYP7A1 and more efficiently enter the enterohepatic circulation via taurine conjugation.

\section{Materials and Methods}

\subsection{Animal Experiments}

Animal experiments were approved by the Ethics Review Committee for Animal Experimentation at Tokyo University of Science (approval numbers: Y18058, Y19055, and Y20044). Mice were maintained under specific-pathogen-free conditions at $23^{\circ} \mathrm{C}$ and a $12 \mathrm{~h}$ light/dark cycle in the animal facility at the Faculty of Pharmaceutical Sciences, Tokyo University of Science. They had free access to water and were fed a Charles River Formula-1 (CRF-1) diet (21.9\% crude protein, 5.4\% crude fat, and 2.9\% crude fiber; Oriental Yeast, Tokyo, Japan) or CRF-1 supplemented with 5\% taurine (Fujifilm Wako Pure Chemical, Osaka, Japan). Male 3-week-old C57BL/6J mice were purchased from CLEA Japan (Tokyo, Japan) and divided into two groups: one was a Chow group fed the CRF-1 diet, while the other was a TauD group fed CRF-1 supplemented with taurine. During rearing, body weight and food intake of the two groups were continuously measured. At 18 weeks of age, resting oxygen consumption and resting carbon dioxide output were measured using an MK-5000RQ (Muromachi Kikai Co., Ltd., Tokyo, Japan) and the RER was calculated. At this time, a GTT was performed. Two days later, an ITT was performed. At 20 weeks of age, body weight of the two groups was measured after euthanasia with isoflurane anesthesia (Mylan, Canonsburg, PA, USA). The last third of the harvested small intestine was separated as the ileum. Subsequently, the ileum was incised vertically and its mucosa 
was scraped and removed. The other tissues were collected, washed using phosphatebuffered saline (PBS), and weighed. Then, tissue samples were minced, snap-frozen in liquid nitrogen, and stored at $-80^{\circ} \mathrm{C}$ until use. Blood samples were mixed with $100 \mathrm{mM}$ EDTA and centrifuged at $2500 \times \mathrm{g}$ for $10 \mathrm{~min}$ at $4{ }^{\circ} \mathrm{C}$. The supernatant was collected as plasma samples and stored at $-80^{\circ} \mathrm{C}$ until analysis.

\subsection{Plasma Biochemical Analysis}

Plasma glucose, TG, NEFA, cholesterol, total bile acid, and FGF21 levels were measured using Autokit Glucose CII (Fujifilm Wako Pure Chemical, Osaka, Japan), LabAssay Triglyceride (Fujifilm Wako Pure Chemical, Osaka, Japan), LabAssay NEFA (Fujifilm Wako Pure Chemical, Osaka, Japan), LabAssay Cholesterol (Fujifilm Wako Pure Chemical, Osaka, Japan), Total Bile Acid Assay Kit (Cell Biolabs, San Diego, CA, USA), and Mouse/Rat FGF21 Quantikine ELISA kit (R \& D Systems, Minneapolis, MN, USA), respectively. All assays were performed in accordance with the manufacturers' protocols.

\subsection{Quantitative RT-PCR}

Total RNA was extracted from frozen liver, ileum, or cells using ISOGEN II (Nippon Gene, Toyama, Japan), and reverse transcription was performed using ReverTra Ace qPCR RT Master Mix (Toyobo, Osaka, Japan). Quantitative PCR was performed using the CFX Connect ${ }^{\mathrm{TM}}$ Real Time System (Bio-Rad, Hercules, CA, USA) and Thunderbird SYBR qPCR Mix (Toyobo, Osaka, Japan), in accordance with the manufacturers' protocols. Quantitative PCR data were processed using a standard curve method. TATA binding protein (Tbp) or Ribosomal protein S18 (Rps18) was used as a housekeeping gene. Sequences of the primers used for PCR are shown in Table 1.

Table 1. List of primers for RT-PCR.

\begin{tabular}{|c|c|c|}
\hline Genes & Forward $\left(5^{\prime}\right.$ to $\left.3^{\prime}\right)$ & Reverse $\left(5^{\prime}\right.$ to $\left.3^{\prime}\right)$ \\
\hline Cyp7a1 & AGCAACTAAACAACCTGCCAGTACTA & GTCCGGATATTCAAGGATGCA \\
\hline$F g f 21$ & GAAGCCCACCTGGAGATCAG & CAAAGTGAGGCGATCCATAGAG \\
\hline Fxr & CCAACCTGGGTTTCTACCC & CACACAGCTCATCСССТTT \\
\hline Shp & CGATCCTCTTCAACCCAGATG & AGGGCTCCAAGACTTCACACA \\
\hline Lrh-1 & ACTGAGAAATTCGGACAGCTACTTC & AGGTAGTCTTCTGCCTGCTTGCT \\
\hline Fgfr4 & GACCAAACCAGCACCGTGGCTGTGAAGATG & GTTTCCCTTGGCGGCACATTCCACAATCAC \\
\hline Klb & CACTGTGGGACACAACCTGA & CCAAGCACAGAGGACATGGA \\
\hline Fgf15 & ACCGCTCCTTCTTTGAAAC & TACATССТССАССАТССТGAAC \\
\hline Tbp & CAGTACAGCAATCAACATCTCAGC & CAAGTTTACAGCCAAGATTCACG \\
\hline Rps18 & TGCGAGTACTCAACACCAACAT & СТTТССТСАAСАССАСАTGAGC \\
\hline
\end{tabular}

\subsection{Immunoblotting}

Protein extraction and Western blotting were performed as described in our previous report [71]. Briefly, livers were homogenized in SDS sample buffer $(50 \mathrm{~mm}$ Tris- $\mathrm{HCl}(\mathrm{pH}$ 6.8 ), $2 \%$ SDS, $3 \mathrm{M}$ urea, $6 \%$ glycerol), centrifuged at $12,000 \times g$ for $30 \mathrm{~min}$ at $4{ }^{\circ} \mathrm{C}$, and the supernatant was boiled for $5 \mathrm{~min}$. Cells were lysed in SDS sample buffer, boiled for $5 \mathrm{~min}$, and sonicated. Lysates were subjected to SDS/PAGE and separated proteins were transferred to nitrocellulose membranes. Membranes were blocked with blocking solution (2.5\% skim milk, $0.25 \%$ BSA in TTBS ( $25 \mathrm{mM}$ Tris- $\mathrm{HCl}$ [pH 7.4], $140 \mathrm{mM} \mathrm{NaCl}, 2.5 \mathrm{mM}$ $\mathrm{KCl}, 0.1 \%$ Tween-20)) for $60 \mathrm{~min}$ at room temperature and then probed with appropriate primary antibodies overnight at $4{ }^{\circ} \mathrm{C}$. The anti-phospho ERK1 pT202/ERK2 pT185 (\#4370), anti-ERK 1/2 (\#9102), and anti-phospho JNK (\#4668) antibodies were purchased from Cell Signaling Technology (Danvers, MA, USA); the anti-Glyceraldehyde 3-phosphate dehydrogenase (GAPDH) antibody (010-25521) was purchased from Fujifilm Wako Pure Chemical, Osaka, Japan; and the anti-JNK (sc-7345) and anti-Hepatocyte Nuclear Factor 4 alpha (HNF4 $\alpha$ ) antibodies (sc-6556) were purchased from Santa Cruz Biotechnology (Dallas, TX, USA). After probing with primary antibodies, membranes were incubated with 
appropriate secondary antibodies for $60 \mathrm{~min}$ at room temperature. The used secondary antibodies were horseradish peroxidase-conjugated $\mathrm{F}\left(\mathrm{ab}^{\prime}\right) 2$ fragment of goat anti-mouse IgG or anti-rabbit IgG (Jackson ImmunoResearch, West Grove, PA, USA). Antibody-bound proteins were visualized using ImmunoStar LD Reagent (Fujifilm Wako Pure Chemical, Osaka, Japan) and a LAS3000 Image Analyzer (Fujifilm, Tokyo, Japan), and data were analyzed using multigauge software (Fujifilm, Tokyo, Japan).

\subsection{Cell Culture and Treatment}

Hepa1-6 cells were purchased from RIKEN Bioresource Center (Ibaraki, Japan). Hepa1-6 cells were maintained in Dulbecco's Modified Eagle Medium (D-MEM) (High Glucose) (Fujifilm Wako Pure Chemical, Osaka, Japan) supplemented with 10\% fetal bovine serum (FBS) (Capricorn Scientific, Ebsdorfergrund, Germany) and 1\% penicillin/streptomycin (Sigma, $\mathrm{MO}$, USA) under a humidified incubator with $5 \% \mathrm{CO}_{2}$ at $37^{\circ} \mathrm{C}$. For the analysis, Hepa1-6 cells were treated with taurine (Fujifilm Wako Pure Chemical, Osaka, Japan) for $24 \mathrm{~h}$ and then collected. The applied concentration is shown in the legends of Figure 3 and Figure S5.

\subsection{Luciferase Assay for Cyp7a1 Promoter Activity}

The Cyp7a1 promoter-driven firefly luciferase plasmid (pGL4.10-Cyp7a1) was generated as follows. The fragments of the Cyp7a1 promoter region $(-376 /+32)$, as identified in a previous study [25], were amplified from rat genomic DNA using KOD FX Neo (Toyobo, Osaka, Japan) with the following primers: forward primer 5'-TTT TGG GAA GCT TCT GCC TGT TT- $3^{\prime}$ and reverse primer $5^{\prime}$-CCC TGC AAA AGC AGG AAA ATT TCC AAA GGG G-3'. Underlined letters represent XhoI and BglII sites, respectively. The generated insert was digested with XhoI and BglII and then subcloned into pGL4.10 (Promega, Madison, WI, USA) digested with the same enzymes. The luciferase assay was performed using Dual-Luciferase Reporter Assay System (Promega, Madison, WI, USA), in accordance with the manufacturer's protocol. In brief, 0.5-1.1 $\times 10^{4}$ Hepa1-6 cells/well were seeded on 96-well plates. After 24-48 h, cells were transfected with pGL4.10-Cyp7a1 and pGL4.74 (Promega, Madison, WI, USA), a plasmid coding HSV-TK promoter-driven Renilla luciferase, using TransIT-2020 Transfection Reagent (Takara, Shiga, Japan) and cultured for 24-72 h. Thereafter, luciferase activity in transfected cells was measured using the above-mentioned kit and an EnVision Multilabel Reader (PerkinElmer, Waltham, MA, USA). The data are shown as the ratio of firefly luminescence to Renilla luminescence (relative luminescent units: RLU).

\subsection{Measurement of Fecal Bile Acids}

Approximately $60 \mathrm{mg}$ of feces was homogenized in $400 \mu \mathrm{L}$ of cold PBS. The homogenates were centrifuged at $10,000 \times g$ for $10 \mathrm{~min}$ at $4{ }^{\circ} \mathrm{C}$. Then, the supernatant was collected, and the bile acid levels were measured using Total Bile Acid Assay Kit (San Diego, CA, USA).

\subsection{Isolation of Nuclear Fractions}

Harvested cell pellets were suspended in buffer A (20 mM HEPES ( $\mathrm{pH} 7.9), 3 \mathrm{mM}$ $\mathrm{MgCl}_{2}, 20 \mathrm{mM} \mathrm{KCl}, 0.68 \mathrm{M}$ sucrose, $20 \%$ glycerol, and $1 \%$ Triton X-100) and incubated on ice for $10 \mathrm{~min}$. Cells were disrupted by pipetting and the suspension was centrifuged at $1300 \times g$ for $5 \mathrm{~min}$. After discarding the supernatant, the precipitate was resuspended in Wash buffer (20 mM HEPES (pH 7.9), $3 \mathrm{mM} \mathrm{MgCl} 2,20 \mathrm{mM} \mathrm{KCl}, 0.68 \mathrm{M}$ sucrose, and $20 \%$ glycerol) and centrifuged at $1300 \times g$ for $4 \mathrm{~min}$. The supernatant was discarded, and the precipitate was resuspended in Wash buffer and centrifuged again at $1300 \times g$ for $4 \mathrm{~min}$. The precipitate was obtained as the nuclear fraction. 


\subsection{Statistical Analyses}

All data are expressed as mean \pm standard deviation (SD). Statistical significance was determined by Student's $t$-test or Dunnett's test. Differences were considered significant at $p<0.05$.

Supplementary Materials: The following supporting information can be downloaded at: https: //www.mdpi.com/article/10.3390/ijms23031793/s1.

Author Contributions: Conceptualization, M.K. and Y.H.; formal analysis, H.K. and Y.M.; funding acquisition, Ryoma Tagawa, M.K. and Y.H.; investigation, M.S. and M.Y.; project administration, and Y.H.; supervision, N.O. and Y.S.; writing—original draft, R.T.; writing—review \& editing, M.K. and Y.N. All authors have read and agreed to the published version of the manuscript.

Funding: This research was funded by the Japan Society for the Promotion of Science (grant No. 20K19581 (to R.T.), No. 20K19686 (to M.K.), and No. 20H04130 (to Y.H.)) and the MEXT Supported Program for the Strategic Research Foundation at Private Universities, 2014-2018.

Institutional Review Board Statement: Animal experiments were approved by the Ethics Review Committee for Animal Experimentation at Tokyo University of Science (approval numbers: Y18058, Y19055, and Y20044).

Informed Consent Statement: Not applicable.

Data Availability Statement: Not applicable.

Acknowledgments: We thank all members of the Laboratory of Molecular Pathology and Metabolic Disease (Faculty of Pharmaceutical Sciences, Tokyo University of Science) for their cooperation and Edanz Group (https:/ /jp-author-services.edanz.com/ (accessed on 24 December 2021)) for editing a draft of this manuscript.

Conflicts of Interest: The authors declare no conflict of interest.

\section{References}

1. Kaste, M.; Koivisto, P. Risk of brain infarction in familial hypercholesterolemia. Stroke 1988, 19, 1097-1100. [CrossRef]

2. Austin, M.A.; Hutter, C.M.; Zimmern, R.L.; Humphries, S.E. Familial hypercholesterolemia and coronary heart disease: A HuGE association review. Am. J. Epidemiol. 2004, 160, 421-429. [CrossRef]

3. Kuai, R.; Li, D.; Chen, Y.E.; Moon, J.J.; Schwendeman, A. High-density lipoproteins: Nature's multifunctional nanoparticles. ACS Nano 2016, 10, 3015-3041. [CrossRef]

4. Chico, Y.; Fresnedo, O.; Lacort, M.; Ochoa, B. Effect of estradiol and progesterone on cholesterol $7 \alpha$-hydroxylase activity in rats subjected to different feeding conditions. Steroids. 1994, 59, 528-535. [CrossRef]

5. Chico, Y.; Fresnedo, O.; Botham, K.; Lacort, M.; Ochoa, B. Regulation of bile acid synthesis by estradiol and progesterone in primary cultures of rat hepatocytes. Exp. Clin. Endocrinol. Diabetes 1996, 104, 137-144. [CrossRef]

6. Theiler-Schwetz, V.; Zaufel, A.; Schlager, H.; Obermayer-Pietsch, B.; Fickert, P.; Zollner, G. Bile acids and glucocorticoid metabolism in health and disease. Biochim. Biophys. Acta Mol. Basis Dis. 2019, 1865, 243-251. [CrossRef]

7. Morimoto, K.; Itoh, H.; Watanabe, M. Developments in understanding bile acid metabolism. Expert. Rev. Endocrinol. Metab. 2013, 8, 59-69. [CrossRef] [PubMed]

8. Bonde, Y.; Eggertsen, G.; Rudling, M. Mice abundant in muricholic bile acids show resistance to dietary induced steatosis, weight gain, and to impaired glucose metabolism. PLoS ONE 2016, 11, e0147772. [CrossRef]

9. Bertaggia, E.; Jensen, K.K.; Castro-Perez, J.; Xu, Y.; Di Paolo, G.; Chan, R.B.; Wang, L.; Haeusler, R.A. Cyp8b1 ablation prevents Western diet-induced weight gain and hepatic steatosis because of impaired fat absorption. Am. J. Physiol. Endocrinol. Metab. 2017, 313, E121-E133. [CrossRef] [PubMed]

10. Chen, W.; Nishimura, N.; Oda, H.; Yokogoshi, H. Effect of taurine on cholesterol degradation and bile acid pool in rats fed a high-cholesterol diet. Adv. Exp. Med. Biol. 2003, 526, 261-267. [CrossRef]

11. Watanabe, M.; Houten, S.M.; Wang, L.; Moschetta, A.; Mangelsdorf, D.J.; Heyman, R.A.; Moore, D.D.; Auwerx, J. Bile acids lower triglyceride levels via a pathway involving FXR, SHP, and SREBP-1c. J. Clin. Investig. 2004, 113, 1408-1418. [CrossRef]

12. Watanabe, M.; Houten, S.M.; Mataki, C.; Christoffolete, M.A.; Kim, B.W.; Sato, H.; Messaddeq, N.; Harney, J.W.; Ezaki, O.; Kodama, T.; et al. Bile acids induce energy expenditure by promoting intracellular thyroid hormone activation. Nature 2006, 439, 484-489. [CrossRef]

13. Matsuzaki, J.; Suzuki, H.; Tsugawa, H.; Watanabe, M.; Hossain, S.; Arai, E.; Saito, Y.; Sekine, S.; Akaike, T.; Kanai, Y.; et al. Bile acids increase levels of microRNAs 221 and 222, leading to degradation of CDX2 during esophageal carcinogenesis. Gastroenterology 2013, 145, 1300-1311. [CrossRef] [PubMed] 
14. Ichikawa, R.; Takayama, T.; Yoneno, K.; Kamada, N.; Kitazume, M.T.; Higuchi, H.; Matsuoka, K.; Watanabe, M.; Itoh, H.; Kanai, T.; et al. Bile acids induce monocyte differentiation toward interleukin-12 hypo-producing dendritic cells via a TGR5-dependent pathway. Immunology 2012, 136, 153-162. [CrossRef]

15. Lan, T.; Morgan, D.A.; Rahmouni, K.; Sonoda, J.; Fu, X.; Burgess, S.C.; Holland, W.L.; Kliewer, S.A.; Mangelsdorf, D.J. FGF19, FGF21, and an FGFR1/ $\beta$-klotho-activating antibody act on the nervous system to regulate body weight and glycemia. Cell Metab. 2017, 26, 709-718.e3. [CrossRef] [PubMed]

16. Chiang, J.Y.L.; Ferrell, J.M. Up to date on cholesterol 7 alpha-hydroxylase (CYP7A1) in bile acid synthesis. Liver Res. 2020, 4 , 47-63. [CrossRef] [PubMed]

17. Chiang, J.Y. Bile acids: Regulation of synthesis. J. Lipid Res. 2009, 50, 1955-1966. [CrossRef]

18. Ahmad, T.R.; Haeusler, R.A. Bile acids in glucose metabolism and insulin signalling-Mechanisms and research needs. Nat. Rev. Endocrinol. 2019, 15, 701-712. [CrossRef] [PubMed]

19. Al-Aqil, F.A.; Monte, M.J.; Peleteiro-Vigil, A.; Briz, O.; Rosales, R.; González, R.; Aranda, C.J.; Ocón, B.; Uriarte, I.; de Medina, F.S.; et al. Interaction of glucocorticoids with FXR/FGF19/FGF21-mediated ileum-liver crosstalk. Biochim. Biophys. Acta Mol. Basis. Dis. 2018, 1864, 2927-2937. [CrossRef]

20. Kurosu, H.; Choi, M.; Ogawa, Y.; Dickson, A.S.; Goetz, R.; Eliseenkova, A.V.; Mohammadi, M.; Rosenblatt, K.P.; Kliewer, S.A.; Kuro-o, M. Tissue-specific expression of $\beta$ Klotho and fibroblast growth factor (FGF) receptor isoforms determines metabolic activity of FGF19 and FGF21. J. Biol. Chem. 2007, 282, 26687-26695. [CrossRef] [PubMed]

21. Wang, L.; Lee, Y.K.; Bundman, D.; Han, Y.; Thevananther, S.; Kim, C.S.; Chua, S.S.; Wei, P.; Heyman, R.A.; Karin, M.; et al. Redundant pathways for negative feedback regulation of bile acid production. Dev. Cell 2002, 2, 721-731. [CrossRef]

22. Gupta, S.; Stravitz, R.T.; Dent, P.; Hylemon, P.B. Down-regulation of cholesterol $7 \alpha$-hydroxylase (CYP7A1) gene expression by bile acids in primary rat hepatocytes is mediated by the c-Jun N-terminal kinase pathway. J. Biol. Chem. 2001, 276, 15816-15822 [CrossRef] [PubMed]

23. Pullinger, C.R.; Eng, C.; Salen, G.; Shefer, S.; Batta, A.K.; Erickson, S.K.; Verhagen, A.; Rivera, C.R.; Mulvihill, S.J.; Malloy, M.J.; et al. Human cholesterol $7 \alpha$-hydroxylase (CYP7A1) deficiency has a hypercholesterolemic phenotype. J. Clin. Investig. 2002, 110, 109-117. [CrossRef]

24. Chiang, J.Y.L.; Ferrell, J.M. Bile acid biology, pathophysiology, and therapeutics. Clin. Liver Dis. 2020, 15, 91-94. [CrossRef] [PubMed]

25. De Fabiani, E.; Mitro, N.; Anzulovich, A.C.; Pinelli, A.; Galli, G.; Crestani, M. The negative effects of bile acids and tumor necrosis factor- $\alpha$ on the transcription of cholesterol $7 \alpha$-hydroxylase gene (CYP7A1) converge to hepatic nuclear factor-4: A novel mechanism of feedback regulation of bile acid synthesis mediated by nuclear receptors. J. Biol. Chem. 2001, 276, 30708-30716. [CrossRef] [PubMed]

26. Kharitonenkov, A.; Shiyanova, T.L.; Koester, A.; Ford, A.M.; Micanovic, R.; Galbreath, E.J.; Sandusky, G.E.; Hammond, L.J.; Moyers, J.S.; Owens, R.A.; et al. FGF-21 as a novel metabolic regulator. J. Clin. Investig. 2005, 115, 1627-1635. [CrossRef] [PubMed]

27. Nishimura, T.; Nakatake, Y.; Konishi, M.; Itoh, N. Identification of a novel FGF, FGF-21, preferentially expressed in the liver. Biochim. Biophys. Acta 2000, 1492, 203-206. [CrossRef]

28. Ding, X.; Boney-Montoya, J.; Owen, B.M.; Bookout, A.L.; Coate, K.C.; Mangelsdorf, D.J.; Kliewer, S.A. $\beta$ Klotho is required for fibroblast growth factor 21 effects on growth and metabolism. Cell Metab. 2012, 16, 387-393. [CrossRef]

29. Ogawa, Y.; Kurosu, H.; Yamamoto, M.; Nandi, A.; Rosenblatt, K.P.; Goetz, R.; Eliseenkova, A.V.; Mohammadi, M.; Kuro-o, M. $\beta$ Klotho is required for metabolic activity of fibroblast growth factor 21. Proc. Natl. Acad. Sci. USA 2007, 104, 7432-7437. [CrossRef] [PubMed]

30. Coskun, T.; Bina, H.A.; Schneider, M.A.; Dunbar, J.D.; Hu, C.C.; Chen, Y.; Moller, D.E.; Kharitonenkov, A. Fibroblast growth factor 21 corrects obesity in mice. Endocrinology 2008, 149, 6018-6027. [CrossRef] [PubMed]

31. Badman, M.K.; Pissios, P.; Kennedy, A.R.; Koukos, G.; Flier, J.S.; Maratos-Flier, E. Hepatic fibroblast growth factor 21 is regulated by PPAR $\alpha$ and is a key mediator of hepatic lipid metabolism in ketotic states. Cell Metab. 2007, 5, 426-437. [CrossRef] [PubMed]

32. Inagaki, T.; Dutchak, P.; Zhao, G.; Ding, X.; Gautron, L.; Parameswara, V.; Li, Y.; Goetz, R.; Mohammadi, M.; Esser, V.; et al. Endocrine regulation of the fasting response by PPAR $\alpha$-mediated induction of fibroblast growth factor 21. Cell Metab. 2007, 5, 415-425. [CrossRef]

33. Potthoff, M.J.; Inagaki, T.; Satapati, S.; Ding, X.; He, T.; Goetz, R.; Mohammadi, M.; Finck, B.N.; Mangelsdorf, D.J.; Kliewer, S.A.; et al. FGF21 induces PGC-1 $\alpha$ and regulates carbohydrate and fatty acid metabolism during the adaptive starvation response. Proc. Natl. Acad. Sci. USA 2009, 106, 10853-10858. [CrossRef] [PubMed]

34. Chen, M.M.; Hale, C.; Stanislaus, S.; Xu, J.; Véniant, M.M. FGF21 acts as a negative regulator of bile acid synthesis. J. Endocrinol. 2018, 237, 139-152. [CrossRef]

35. Kim, K.H.; Lee, M.S. FGF21 as a stress hormone: The roles of FGF21 in stress adaptation and the treatment of metabolic diseases. Diabetes Metab. J. 2014, 38, 245-251. [CrossRef]

36. Zhang, X.; Yeung, D.C.; Karpisek, M.; Stejskal, D.; Zhou, Z.G.; Liu, F.; Wong, R.L.; Chow, W.S.; Tso, A.W.; Lam, K.S.; et al. Serum FGF21 levels are increased in obesity and are independently associated with the metabolic syndrome in humans. Diabetes 2008, 57, 1246-1253. [CrossRef] [PubMed] 
37. Dushay, J.; Chui, P.C.; Gopalakrishnan, G.S.; Varela-Rey, M.; Crawley, M.; Fisher, F.M.; Badman, M.K.; Martinez-Chantar, M.L.; Maratos-Flier, E. Increased fibroblast growth factor 21 in obesity and nonalcoholic fatty liver disease. Gastroenterology 2010, 139, 456-463. [CrossRef] [PubMed]

38. Zhou, Y.; Holmseth, S.; Guo, C.; Hassel, B.; Höfner, G.; Huitfeldt, H.S.; Wanner, K.T.; Danbolt, N.C. Deletion of the $\gamma$-aminobutyric acid transporter 2 (GAT2 and SLC6A13) gene in mice leads to changes in liver and brain taurine contents. J. Biol. Chem. 2012, 287, 35733-35746. [CrossRef]

39. Yamaguchi, K.; Hosokawa, Y. Cysteine dioxygenase. Methods Enzymol. 1987, 143, 395-403. [CrossRef]

40. Huxtable, R.J. Physiological actions of taurine. Physiol. Rev. 1992, 72, 101-163. [CrossRef]

41. Bai, J.; Yao, X.; Jiang, L.; Zhang, Q.; Guan, H.; Liu, S.; Wu, W.; Qiu, T.; Gao, N.; Yang, L.; et al. Taurine protects against As2O3-induced autophagy in livers of rat offsprings through PPAR $\gamma$ pathway. Sci. Rep. 2016, 6, 27733. [CrossRef]

42. Li, Y.; Hu, Z.; Chen, B.; Bu, Q.; Lu, W.; Deng, Y.; Zhu, R.; Shao, X.; Hou, J.; Zhao, J.; et al. Taurine attenuates methamphetamineinduced autophagy and apoptosis in PC12 cells through mTOR signaling pathway. Toxicol. Lett. 2012, 215, 1-7. [CrossRef] [PubMed]

43. Kaneko, H.; Kobayashi, M.; Mizunoe, Y.; Yoshida, M.; Yasukawa, H.; Hoshino, S.; Itagawa, R.; Furuichi, T.; Okita, N.; Sudo, Y.; et al. Taurine is an amino acid with the ability to activate autophagy in adipocytes. Amino Acids 2018, 50, 527-535. [CrossRef]

44. Fengyan Piao, I.-U.-L.; Aadil, R.M.; Suleman, R.; Li, K.; Zhang, M.; Wu, P.; Shahbaz, M.; Ahmed, Z. Ameliorative effects of taurine against diabetes: A review. Amino Acids 2018, 50, 487-502. [CrossRef]

45. Morsy, M.D.; Aboonq, M.S.; ALsleem, M.A.; Abusham, A.A. Taurine prevents high-fat diet-induced-hepatic steatosis in rats by direct inhibition of hepatic sterol regulatory element-binding proteins and activation of AMPK. Clin. Exp. Pharmacol. Physiol. 2020, 48, 72-85. [CrossRef] [PubMed]

46. Dong, Y.; Li, X.; Liu, Y.; Gao, J.; Tao, J. The molecular targets of taurine confer anti-hyperlipidemic effects. Life Sci. 2021, 278, 119579. [CrossRef] [PubMed]

47. Yokogoshi, H.; Mochizuki, H.; Nanami, K.; Hida, Y.; Miyachi, F.; Oda, H. Dietary taurine enhances cholesterol degradation and reduces serum and liver cholesterol concentrations in rats fed a high-cholesterol diet. J. Nutr. 1999, 129, 1705-1712. [CrossRef] [PubMed]

48. Murakami, S.; Kondo, Y.; Toda, Y.; Kitajima, H.; Kameo, K.; Sakono, M.; Fukuda, N. Effect of taurine on cholesterol metabolism in hamsters: Up-regulation of low density lipoprotein (LDL) receptor by taurine. Life Sci. 2002, 70, 2355-2366. [CrossRef]

49. Chen, W.; Guo, J.X.; Chang, P. The effect of taurine on cholesterol metabolism. Mol. Nutr. Food Res. 2012, 56, 681-690. [CrossRef]

50. Danielsson, H. Present status of research on catabolism and excretion of cholesterol. Adv. Lipid Res. 1963, 1, 335-385. [CrossRef] [PubMed]

51. Sjovall, J. Dietary glycine and taurine on bile acid conjugation in man; bile acids and steroids 75. Proc. Soc. Exp. Biol. Med. 1959, 100, 676-678. [CrossRef]

52. Miyazaki, T.; Sasaki, S.I.; Toyoda, A.; Wei, F.Y.; Shirai, M.; Morishita, Y.; Ikegami, T.; Tomizawa, K.; Honda, A. Impaired bile acid metabolism with defectives of mitochondrial-tRNA taurine modification and bile acid taurine conjugation in the taurine depleted cats. Sci. Rep. 2020, 10, 4915. [CrossRef]

53. Abd Elwahab, A.H.; Ramadan, B.K.; Schaalan, M.F.; Tolba, A.M. A novel role of SIRT1/ FGF-21 in taurine protection against cafeteria diet-induced steatohepatitis in rats. Cell Physiol. Biochem. 2017, 43, 644-659. [CrossRef] [PubMed]

54. Keinicke, H.; Sun, G.; Mentzel, C.M.J.; Fredholm, M.; John, L.M.; Andersen, B.; Raun, K.; Kjaergaard, M. FGF21 regulates hepatic metabolic pathways to improve steatosis and inflammation. Endocr. Connect. 2020, 9, 755-768. [CrossRef] [PubMed]

55. Zhang, J.; Gupte, J.; Gong, Y.; Weiszmann, J.; Zhang, Y.; Lee, K.J.; Richards, W.G.; Li, Y. Chronic over-expression of fibroblast growth factor 21 increases bile acid biosynthesis by opposing FGF15/19 action. EBioMedicine 2017, 15, 173-183. [CrossRef] [PubMed]

56. Adams, A.C.; Cheng, C.C.; Coskun, T.; Kharitonenkov, A. FGF21 requires $\beta$ klotho to act in vivo. PLoS ONE 2012, 7, e49977. [CrossRef]

57. Adams, A.C.; Yang, C.; Coskun, T.; Cheng, C.C.; Gimeno, R.E.; Luo, Y.; Kharitonenkov, A. The breadth of FGF21's metabolic actions are governed by FGFR1 in adipose tissue. Mol. Metab. 2012, 2, 31-37. [CrossRef]

58. Suzuki, M.; Uehara, Y.; Motomura-Matsuzaka, K.; Oki, J.; Koyama, Y.; Kimura, M.; Asada, M.; Komi-Kuramochi, A.; Oka, S.; Imamura, T. $\beta$ Klotho is required for fibroblast growth factor (FGF) 21 signaling through FGF receptor (FGFR) 1c and FGFR3c Mol. Endocrinol. 2008, 22, 1006-1014. [CrossRef]

59. Wu, S.; Levenson, A.; Kharitonenkov, A.; De Luca, F. Fibroblast growth factor 21 (FGF21) inhibits chondrocyte function and growth hormone action directly at the growth plate. J. Biol. Chem. 2012, 287, 26060-26067. [CrossRef]

60. Veto, B.; Bojcsuk, D.; Bacquet, C.; Kiss, J.; Sipeki, S.; Martin, L.; Buday, L.; Bálint, B.L.; Arányi, T. The transcriptional activity of hepatocyte nuclear factor 4 alpha is inhibited via phosphorylation by ERK1/2. PLoS ONE 2017, 12, e0172020. [CrossRef]

61. Chandra, V.; Holla, P.; Ghosh, D.; Chakrabarti, D.; Padigaru, M.; Jameel, S. The hepatitis E virus ORF3 protein regulates the expression of liver-specific genes by modulating localization of hepatocyte nuclear factor 4. PLoS ONE 2011, 6, e22412. [CrossRef] [PubMed]

62. Guo, J.; Gao, Y.; Cao, X.; Zhang, J.; Chen, W. Cholesterol-lowing effect of taurine in HepG2 cell. Lipids Health Dis. 2017, 16, 56. [CrossRef] [PubMed] 
63. Jiang, G.; Nepomuceno, L.; Hopkins, K.; Sladek, F.M. Exclusive homodimerization of the orphan receptor hepatocyte nuclear factor 4 defines a new subclass of nuclear receptors. Mol. Cell. Biol. 1995, 15, 5131-5143. [CrossRef]

64. Guan, D.; Zhao, L.; Chen, D.; Yu, B.; Yu, J. Regulation of fibroblast growth factor 15/19 and 21 on metabolism: In the fed or fasted state. J. Transl. Med. 2016, 14, 63. [CrossRef]

65. Miyata, M.; Tanaka, T.; Takahashi, K.; Funaki, A.; Sugiura, Y. Cholesterol-lowering effects of taurine through the reduction of ileal FXR signaling due to the alteration of ileal bile acid composition. Amino Acids 2021, 53, 1523-1532. [CrossRef]

66. Odermatt, A.; Klusonova, P. 11 $\beta$-Hydroxysteroid dehydrogenase 1: Regeneration of active glucocorticoids is only part of the story. J. Steroid Biochem. Mol. Biol. 2015, 151, 85-92. [CrossRef] [PubMed]

67. Schweizer, R.A.; Zürcher, M.; Balazs, Z.; Dick, B.; Odermatt, A. Rapid hepatic metabolism of 7-ketocholesterol by 11ßhydroxysteroid dehydrogenase type 1: Species-specific differences between the rat, human, and hamster enzyme. J. Biol. Chem. 2004, 279, 18415-18424. [CrossRef] [PubMed]

68. Hult, M.; Elleby, B.; Shafqat, N.; Svensson, S.; Rane, A.; Jörnvall, H.; Abrahmsen, L.; Oppermann, U. Human and rodent type 1 $11 \beta$-hydroxysteroid dehydrogenases are $7 \beta$-hydroxycholesterol dehydrogenases involved in oxysterol metabolism. Cell Mol. Life Sci. 2004, 61, 992-999. [CrossRef] [PubMed]

69. Uozumi, Y.; Ito, T.; Takahashi, K.; Matsuda, T.; Mohri, T.; Kimura, Y.; Fujio, Y.; Azuma, J. Myogenic induction of taurine transporter prevents dexamethasone-induced muscle atrophy. Adv. Exp. Med. Biol. 2006, 583, 265-270. [CrossRef] [PubMed]

70. Hirata, H.; Ueda, S.; Ichiseki, T.; Shimasaki, M.; Ueda, Y.; Kaneuji, A.; Kawahara, N. Taurine inhibits glucocorticoid-induced bone mitochondrial injury, preventing osteonecrosis in rabbits and cultured osteocytes. Int. J. Mol. Sci. 2020, 21, 6892. [CrossRef]

71. Mizunoe, Y.; Kobayashi, M.; Sudo, Y.; Watanabe, S.; Yasukawa, H.; Natori, D.; Hoshino, A.; Negishi, A.; Okita, N.; Komatsu, M.; et al. Trehalose protects against oxidative stress by regulating the Keap1-Nrf2 and autophagy pathways. Redox Biol. 2018, 15, 115-124. [CrossRef] 